\title{
Integrated Centripetal Forces: A Study on the Benefits that Australian Learning and Teaching Centers (LTCs) will Contribute to the Development of Double First-rate Universities in China
}

\author{
Liangliang Wang ${ }^{1}$, Mingfang Fan ${ }^{1}$, \& Feng Zhang ${ }^{2}$ \\ ${ }^{1}$ School of Humanities, Economics and Law, Northwestern Polytechnical University, Xi'an, P.R.China \\ ${ }^{2}$ School of Mechanics, Civil Engineering \& Achitechture, Northwestern Polytechnical University, Xi'an, \\ P.R.China \\ Correspondence: Liangliang Wang, Mailbox 883, Dong-Xiang Road, School of Humanities, Economics and Law, \\ Northwestern Polytechnical University, Xi'an, Shaanxi, P. R. China. Tel: (+) 86 (0) 29-88431909. E-mail: \\ celia.liangliang.wang@hotmail.com
}

Received: July 16, 2017 Accepted: August 8, $2017 \quad$ Online Published: August 25, 2017

doi:10.5539/ass.v13n9p1 URL: https://doi.org/10.5539/ass.v13n9p1

\begin{abstract}
An investigation of eight university-based Learning and Teaching Centers (LTCs) at Australian top-tier universities could provide benefits for the development of China's Double First-rate universities. This paper contributes to our understanding of integrated centripetal forces in four ways. Firstly, we describe integrated organizational centripetal force. Then, we examine integrated staff centripetal force, which imply that LTCs regard teacher education as dynamic, sustainable processes providing enriched teaching and professional developmental resources. Next, LTCs facilitate the integrated discipline centripetal force that reveals the required technical guidance and identification of academic leaders. Finally, we realize the integrated centripetal force of the quality of education resulting from the development of high-quality learning environments for student engagement and scientific evaluation, and feedback from lecturers' teaching. Therefore, the experience from LTCs can promote the organization and construction of Double First-rate universities, letting teachers respond to students' changing in suitable ways, benefiting academic's centripetal force of self-improvement, producing the centripetal force that benefits both the teacher and the discipline. Eventually, LTCs could fundamentally integrate all stakeholders' centripetal forces in promoting first-class disciplines and first-class universities in China's higher education.
\end{abstract}

Keywords: Centripetal forces, Learning and Teaching Centers (LTCs), Double First-rate universities, Teacher education

\section{Introduction}

\subsection{Introduction the Problem}

Learning and Teaching Centers (LTCs), teacher education institutions in world-class universities, have played important roles in institutional development. The University of Michigan sets up the first Teaching and Learning Center entitled the Center for Research on Learning and Teaching in 1962 (Center for Research on Learning and Teaching, 2016). In the following decade, Harvard University founded the Derek Bok Center for Teaching and Learning in 1975, which aimed to promote university innovation and practice through teaching and learning (Derek Bok Center for Teaching and Learning, 2016). The Cambridge Centre for Teaching and Learning currently supported teaching by providing training, developing network technologies and hosting a variety of development activities (Cambridge Centre for Teaching and Learning, 2016). In 2009, the Centre for Teaching Support \& Innovation of Toronto University, Canada, provided teaching training for 12,500 academic and 4,300 teaching assistants (Bolan, Bellamy, Rolheiser, Szurmak \& Vine, 2015). Overall, LTCs have made major learning and teaching contributions to these world first-class universities and contributed to their general academic development.

\subsection{Why is the Problem Important?}

Recently, China has been promoting a new orientation for higher education. China's State Council issued one 
program entitled Co-ordination of World-class Universities and First-class Discipline Construction of the Overall Program on November 6, 2015, which aims to build some world-class universities and first-class disciplines and finally enhances the comprehensive strength of China's higher education and international competitiveness (Ministry of Education of the People's Republic of China, 2015). It is an important policy in China because it has been predicted that the policy will benefit the whole development of Chinese higher education and may even have influence on world education. Thus, it is timely and necessary to study the development experience from 'first-class' universities in the world. The research on Teaching and Learning Centers will be an potential necessary part in the process.

\subsection{Centripetal Force}

Centripetal force is a physical concept. According to classical mechanics' terms, it refers to a situation where an object orbiting around the circumference or curved orbit of a body mass is subject to an external force which points to the center of curvature, known as the centripetal force. Centripetal force in the humanities and social science research has been co-opted to mean a measure of the degree of unity and cooperation of group members to group leadership at the centre (Centripetal force, 2016).

The hypothesis of this paper is that the teaching centers could produce a kind of driving force to the goal, achieving the cohesion of the goal, forming the process of supervision, the results of the appeal, and ultimately the form of an integration of centripetal forces for Double First-class universities development. This is because the teaching center can integrate all aspects of the power of the interest groups which include the organizations, teachers, disciplines and students, forming an integrated centripetal force. Based on the data in Quacquarelli Symonds World University Ranking, Academic Ranking of World Universities, eight Australian research universities received high rankings every year, and can be regarded as Australian top-tier universities.

After years of operation and development, the teaching centers of these universities are highly efficient and can be regarded as the main body of this study. If we can research the mature construction experience at these teaching centers in benchmarking universities, this will surely be beneficial for China's Double First-rate universities construction in the future.

\section{Methology}

\subsection{Subjects}

'Despite the legitimacy of the university rankings and scientific questioned ...however, universities that have good rank in the world could play benchmarking roles in the global context and become the study object for other universities (Guo \& Sun, 2015). The data from 2015 Excellence in Research for Australia (ERA), Quacquarelli Symonds World University Ranking (QS), Academic Ranking of World Universities (ARWU), and US News, the following universities were ranked as top-tier universities in Australia. These five-star universities all have their own teaching centers although they use different names for each (see Table 1).

Table 1. Teaching and Learning Centers list in Australia

\begin{tabular}{lcccccc}
\hline \multirow{2}{*}{ University Name } & \multicolumn{9}{c}{ Category } \\
\cline { 2 - 7 } & ERA & QS & ARWU & US News & Center name \\
\hline University of Melbourne & 1 & 42 & 44 & 40 & Centre for Excellent in Learning and Teaching \\
University of Sydney & 2 & 45 & $101+$ & 51 & Institute for Learning and Teaching \\
Australian National University & $3=$ & 19 & $77=$ & $80=$ & Centre for Higher Education, Learning \& Teaching \\
University of Queensland & $3=$ & 46 & $77=$ & 52 & Learning\&Teaching at UQ \\
University of New South Wales & 4 & 46 & $101+$ & $90=$ & Learning and Teaching Unit \\
Monash University & 5 & 67 & $101+$ & $84=$ & Teaching and Learning \\
University of Western Australia & 6 & 98 & 87 & $128=$ & Learning and Teaching \\
University of Adelaide & 7 & 113 & $151+$ & $184=$ & Learning \& Teaching \\
\hline
\end{tabular}

Data resource: Australian Education Network. (Main Australian Rankings Table, 2016) 


\subsection{Analysis Collection}

Primary and secondary data were collected in the study. For the primary data, the authors contacted eight universities' staff by email or through interviews. Secondary data came from these universities' websites and related digital resources. All the information included in the study was checked for reliability and validity.

\subsection{Interpretation}

By analyzing the eight most important five-star universities in Australia, the research aims to analyze the integration of centripetal forces at universities and then in order to find out how centripetal forces promote the universities and also their application possibilities with respect to China's dual-class university construction.

\section{Results}

\subsection{LTCS Integrate Organizational Centripetal Forces through Building of Professional Institutions}

Building Teaching and Learning Centers (LTCs) based on their own development needs, eight Australian universities display the inherent needs of modern institutions, and play important roles in Australian higher education. The LTCs researched included: The Centre for Excellent in Learning and Teaching at the University of Melbourne, the Centre for Higher Education, Learning \& Teaching at Australian National University, Learning \&Teaching at the University of Queensland, the Learning and Teaching Unit at the University of New South Wales, and Learning \& Teaching at the University of Adelaide and so on.

Researching the history of these universities, we found that these centers experienced division and adjustment in different periods. However, no matter how much change they experienced, the universities regarded the LTCs as essential institutions during their own development and construction, due to the notion that professional educational institutions like LTCs not only provide the necessary support for the teaching and learning at university but also produce the centripetal forces aimed at the university's education vision.

In recent years, due to federal budget concerns, education investment and other factors, the LTCs have to frequently change their policies. Taking the University of Sydney as an example, the institute for Teaching and Learning and Sydney e-Learning has been integrated into one new organization, now known as Educational Innovation (Educational Innovation, 2016). All in all, its core purpose was to support the development of higher education.

\subsubsection{Clear Institutional Orientation: Teaching and Learning}

Although there are differences in scale, staff, functional management and other aspects, all LTCs have stressed that their clear functional orientation is teaching and learning. To begin with, the central role of teaching and learning is of teacher, which means the teaching and learning aims at teachers, and its clients are teachers, not students. This differs from the main body of China's educational colleges.

What's more, LTCs illustrate the relationship between teaching and learning. Teachers have to learn specific knowledge of the subject and also learn the conditional knowledge required of a teacher; that is, the process to become effective teachers. While a teaching degree satisfies the former condition, LTCs help to improve the later. Finally, the process of teacher education is a combination of learning and teaching. That is to say, teachers are learners in his/her whole life. Teachers in colleges and universities need to continue to develop new professional knowledge in the course of teaching, study new educational situations, and develop their own professional level after undergoing professional assessment.

\subsubsection{Providing Teachers with Development Experience}

The United Nations Educational, Scientific and Cultural Organization (UNESCO) has consistently focussed on the differences of 'vocation' and 'professional' to advocacy of 'professional status' and 'teacher professional development'. UNESCO has tracked the development of teacher education in developed countries for many years (Zhong, 2008). Specifically, teacher education is a kind of vocational education, which tries to build educational programs and learning experiences together with professional experience (Hoooper, Mitcham, Taff and Price, 2015). LTCs can provide professional experience for teachers within the university, such as providing teachers with professional education programs and educational experience. It not only completes the basic demands of teacher vocational education, but also gives teachers practical guidance. It encourages them to research teaching from the perspective of science, educating students from the perspective of education, and supporting teaching from a professional point of view. On the other hand, LTCs constitute university-based training and guidance for teachers. Teaching and learning practices within LTCs are based on the characteristics of the specific university, the skill level of their own teachers, and the context of the education that teachers facilitate. Considering all relevant factors, teacher education requires a comprehensive grasp of the 
university-based teaching and learning. This allows university teacher education to further support standardization, specialization and integration of knowledge.

\subsection{LTCS Integrate Staff Centripetal Forces through Activation of Teachers' vitality}

Activating the abilities of teachers that eagers to develop their teaching skills and who bring vitality to the process of upgrade them can effectively integrate the potential centripetal force of university staff. In Australia, the reviewed universities are characterized by the provision of improved programs for teaching through comprehensive teacher education programs, adapting data-based evaluation system to enable teachers to teach follow up scientific approaches, letting the teachers understand educational processes that are on the cutting edge of educational philosophy, and developing teachers' professional skills with advanced teaching methods. All of them actively develop the potential of teachers, which in turn makes teacher education more dynamic and sustainable.

\subsubsection{Continuously Dynamic Teacher Education}

Australian teaching centers identify teacher education as dynamic development process: education content covers all aspects of teacher education, which makes the process more scientific and easier to operate; educational reform is not only carried out on regular activities, it is also reflected in a range of flexible ways. In terms of classification, academic teachers have different teacher education programs on professional teachers. Additionally, all the programs consider age and experience facts for staff. Therefore, the development of teacher education maintains a sustainable developmental trend.

Teaching centers provide effective education and training and counseling for teachers through regular delivery of various types of seminars. For example, one program entitled the Teacher and Career Development Service at the University of New South Wales aims to support professional and career development through a series of high quality courses, activities, resources and services. It provides the necessary support and services for teachers at different stages and professional needs, which mainly explores for early-career staff, funds application guidance, and a range of teaching awards (Learning and Teaching Unit, 2016).

Sometimes there are some point-to-point guidance or face to face professional teaching guidance and recommendations. The University of Sydney sets an example in this respect, launching a faculty-based teaching development policy. The team director and faculty director provide consulting services through a series of teaching activities for staff that covers professional development and curriculum planning. At the same time, they establish a Scholars Academic Network where staff can share their educational experience and some observations or confusions, allowing teachers to update their academic knowledge dynamically, and in a timely style (Our work at a glance, 2016).

\subsubsection{Developing Resources and Promoting Teachers' academic Innovation}

The teacher education usually consists of three aspects. Firstly, it shapes teachers' self-role, which includes professional role recognition and professional ethics development. Secondly, it accesses to professional knowledge, including pedagogy and the learn abilities. Thirdly, it is the development of practical wisdom, such as the accumulation of practical experience and self-reflection (Jin \& Xiao, 2014). LTCs at Australian top-tier universities highlight teacher development resources, offering teachers the possibility of implementing innovative teaching solutions and also accessing to academic innovation opportunities. At Monash University, LTC staff were distributed to the faculties, avoiding the stagnation that can occur in centralized teaching services Its purpose is to emphasize the importance and effectiveness of teaching, with an emphasis on innovation (Gardner, 2016).

\subsection{LTCs Integration Discipline Construction Centripetal Forces through Development of Innovative Platforms}

'First-class scholars, first-class students, first-class scientific research, first-class academic reputation, first-class social services' are considered the standard of first-class discipline (Zhou \&Wu, 2016). Discipline is regarded the place and position for teachers' work and is a prerequisite for first-class educational delivery. It is essential for the development of a university as it is an academic innovation platform and kind of discipline construction integration and most importantly it provides centripetal force for such construction.

\subsubsection{Giving Teachers' technical Guidance and Service Discipline}

Enhancing teachers' abilities to adopt new technologies and new skills is an effective way to help teachers improve their subject knowledge. The Williams Centre for Learning Advancement at Melbourne University aims at teacher development, where staff learn about new teaching technologies that can service discipline development. The Centre is fully aware of the characteristics of contemporary college students and realize that 
giving teachers the necessary technical guidance could meet the requirement of students and then services for teaching. The practice is as follows (The Williams Centre for Learning Advancement, 2016):

1) A series of instructional programs for teaching about teaching is conducted;

2) The programs make use of peer review and group work;

3) Instructors emphasize the importance of effective student feedback and evaluation;

4) Participants are encouraged to respect the diversity and varied abilities of students;

5) The programs strengthen teaching based on a variety of educational resources and technologies.

Furthermore, guidance and training for new entrants are mandatory. If teacher complete their own courses, they are certified. Alternatively, if teacher cannot complete the necessary courses, they have to contact the center to carry out a 'one-on-one' review meeting. New teachers and experienced teachers are offered specific guidance and requirements for improving their teaching.

\subsubsection{Advocating Teachers' academic Leadership and Developing Discipline}

An important responsibility of university academics is the development of their discipline. Australian top-tier university teachers hold the concept that the professional development of teachers come from the teaching and learning process of academic leadership, which results in professional excellence for teachers. The core idea of academic leadership is teachers' self-management and/or self-leadership. The Australian National University has established and developed an academic leadership model for teacher instruction, carrying out ten professional activities to help teaching expand and enrich teachers' academic leadership (Introduction to Academic Leadership, 2016), which affirms the value of teachers' academic leadership and helps teachers to develop their own leadership. Only on the basis of a clear understanding of his or her abilities, is it possible to explore the teacher's academic skill, personality, and originality, and then reflect them back onto the development of disciplines that they are teaching.

\subsection{LTCs Integrate Education Quality Centripetal Forces through Promotion of Student Engagement}

Student engagement is an important research field in higher education. More and more countries are recognizing student engagement as one of the more important indicators for the creation of sound development plans for higher education and policy guidelines. At the same time, student engagement is also seen as playing a critical role in teaching effect and as an indicator of the overall quality of education. In fact, it has been proven that LTCs played an import role in the promotion of student engagement and contributed to the centripetal force that integrates the quality of education.

\subsubsection{Developing Quality Learning Environments and Strengthening Student Engagement}

The concept and theory of student engagement originated in North America, which drawn on the theoretical results of modern psychology, using various quantitative indicators, and highlighting the three dimensions of student engagement that include affective engagement, behavioral engagement and cognitive engagement. Some research regard academic development as leadership at institutions (Taylor, 2005). From that, we could see academic engagement is still an important fact in higher education. The Eight Australian top-tier universities actively strengthen and promote student engagement, not only in education, but also in gender issues, educational environments and other aspects such as socio-economic factors related to low-income families and international students at different levels (Routledge, 2009). Student engagement is not only regarded as an educational ideal, but also involves teaching objectives, standards for all teaching activities, and may even be relevant to the mission of the university as a whole. LTCs, though not directly serving the needs of students, spare no effort to strengthen or promote student engagement through teaching activities or corresponding technical resources. The LTC at the University of Western Australia contributed to students' engagement by developing 'STUDYSmarter'. The Centre developed a learning system for academic skills to promote students' learning, language, and other learning environments and to develop students' skills through seminars and other forms of consultation, by clever use of technology. Specifically, 'WRITESmart' focuses on students' writing, research and learning; '(Maths) Smart' focuses on students' academic and data analysis; 'GETSmart' provides some online network resources; and 'QUICKSmart answers' replies to student questions quickly and effectively (STUDYSmarter, 2016). In this sense, the center serves the needs of students and becomes an effective teaching assistant through the development of realistic and virtual teaching environment.

\subsubsection{Guiding Teachers to Scientifically Evaluate Students and to Help Students Engage in Their Learning}

Student evaluation is an effective strategy to encourage student engagement. It can be seen in the the University of Queensland's educational practice which focuses on student assessment to activate student engagement (The 
UQ Student Survey Framework, 2016). Through internal surveys they assess the curriculum and teacher activity from the perspective of students, and external surveys comprehensively consider students' investment in higher education from the student experience, student graduation status and student employment data. Finally, it provides reliable data analysis for the quality of education. An additional LTC measure is focusing on the integrity of the students to improve the mechanism. In another example, the LTC at the University of Adelaide insists that the core concept and the necessary means to promote the high-quality teaching activities of the teaching center is student engagement. It has formulated a 'learning-teaching-evaluation' strategy, which includes seven fields: curriculum, learning, evaluation, teaching, communication and innovation, as well as analysis and evaluation (A Commitment to Learning \& Discovery, 2016). These strategies provide a clear framework for education and instruction and reinforce educational and instructional guidance. It can be said that the LTCs have effectively strengthened student engagement and promoted the quality of higher education.

\section{Discussion}

\subsection{LTCs can Promote the Organization and Construction of Double First-rate Universities}

Based on what has been mentioned, with the construction of 'double first-class' universities, it is possible to realize the university's development vision through the establishment of LTCs. In China, there are three modes of teacher education in colleges and universities, i.e. normal colleges merged into a comprehensive university and became one of its educational faculties or colleges; normal colleges that are upgraded or transformed into a comprehensive university; and normal schools that are defined as university-level independent colleges and that collaborate with universities to self-develop (He, 2013). However, given the current educational background, the above approaches are not suit to the current situation. It is clear that the magnitude of such actions is unrealistic as a developmental response, and its necessity and possibility for implementation are questioned.

Australian top-tier universities produce a kind of centripetal force within universities through the establishment of dedicated teacher education organizations (LTCs) which could be beneficial for 'Double First-rate' university construction. The professional services provided by LTCs have a direct impact on teachers and provide the necessary technical and resource support to the university for teacher development. This model of innovation can get rid of the individual, scattered, random teacher education model and establish complete training system. Teachers ultimately promote the professional development through professional institutions, professionals specialized services, professional courses and professional assessment.

\subsection{LTC can Help Teachers to Respond to Student Changing in Suitable Ways}

In China, although colleges and universities for new teachers provide comprehensive curriculum on teacher education and training, it is only when they have qualified and hold appropriate certification that they can start teaching. However, university teacher education is relatively monotonous, lacking of continuity, it is not enough to stimulate the vitality of teachers and integrate staff potential abilities.

With the diversity of teaching objects and environments becoming more and more prominent, the renewal of educational philosophy more and more important, and the application of educational technology more and more extensive, basic training can not satisfy the teachers' future teaching needs. Some teachers, take the initiative to develop themselves through teacher extension courses, by imitating excellent lesson plans and engaging in other self-learning or self-perception activities. Obviously, this, in itself, is no substitute for a teacher's professional growth chain convergence, and rarely meets the needs of teacher satisfaction. In fact, in the current educational background of dual-class universities, especially given the fact of college students who demonstrate many new diversities, teachers' individual professional growth is obviously not enough because the teachers' individual time, energy and knowledge are limited. Individual teacher will not become expert in all aspects of their profession. They have to rely on effective support and help from other professional colleagues.

\subsection{LTCs can Benefit an Academic's Centripetal Force of Self-improvement}

Teacher education centers can assist in the discovery and development of the centripetal force behind a teacher's self initiative in the construction of the Double First-rate university. If teachers become proficient in business expertise, either as experts or masters, this will not be merely a time-based or self-growth process.

This process of growth is difficult and long, which not only means teachers have to voluntarily learn, actively change their professional roles and strengthen their ontological knowledge, but also requires continuous strengthening and updating of conditional knowledge. In fact, the LTCs can integrate individual development needs and professional development to pave the way for teachers becoming experts in teaching. They encourage teachers to have their own educational philosophy and maintain a unique educational style so as to become the 'expert' teacher who has professional knowledge and can finally complete their fulfilling, transformative career. 


\subsection{LTCs can Produce the Centripetal Force that Benefits the Teacher and the Discipline}

In China there are still some professional course teachers who are good at scientific research but whose teaching level are relatively weak. This is partly due to the fact that some teachers spent more time and energy on scientific research than teaching, or simply lack teaching experience. The fundamental reason is that teachers do not deal with the relationship between professional guidance and academic innovation. The main teaching subjects of these teachers are undergraduates who did not go on to do postgraduate research. A teacher's understanding of the educational process will directly affect students' understanding of professional awareness and exploration. If there are no high-quality students, the major problems for discipline innovation, and then 'first-class discipline' are difficult to achieve.

Furthermore, at this stage, China still has some universities that have good basis for continuing to run, however the teaching in the disciplines is not strong $(\mathrm{Li}, 2016)$. In the course of the development of these universities, they were unable to display their advantages on the construction of major projects, major platforms or key disciplines. The fundamental reason is that the centripetal force integration is not applied effectively to individual strengths and research teams. They only center on cohesion of power and then highlight the institution's characteristics. Thus, with a 'Double First-rate' university construction background, if we can consider the development of innovation models that are based on an academic innovation platform and integrate individual development of innovation, forming solid foundation, it is possible to build truly high standard 'first-rate' disciplines.

\section{Conclusions}

In conclusion, LTCs can form integrated centripetal forces at universities, providing help for staff and students, and ultimately upgrading disciplines and universities as a whole. Under the Chinese current 'Double First-rate' university construction background, if the universities can fully understand and realize the value of LTCs at institutions, scientifically position them and focus on promoting the construction of a university-based teacher education system, they will provide benefits for the development of Chinese universities. LTCs could take leadership roles in the process and show the centripetal forces required for cohesive innovation and development at universities. Finally, LTCs can create platforms for both individual and university-level development because they will make the best use of all kinds of learning and teaching resources.

\section{Acknowledgements}

The authors would like to express appreciation for the support of the sponsors: Chinese Scholarship Council (20153022), Northwestern Polytechnical University Policy and Strategic Research Funding (2017ZCY12) and 2017 Northwestern Polytechnical University Education and Teaching Reform Research Project (2016-502).

\section{References}

A Commitment to Learning \& Discovery (2016). Retrieved from http://www.adelaide.edu.au/learning/.

Bolan, J., Bellamy, P., Rolheiser, C., Szurmak, J., \& Vine, R. (2015). Realizing partnership potential: A report on a formal collaboration between a teaching and learning center and libraries at the University of Toronto. Collected Essays on Learning and Teaching, (VIII), 191-200.

Cambridge Centre for Teaching and Learning (2016). Retrieved from http://www.cctl.cam.ac.uk/.

Center for Research on Learning and Teaching (2016). Retrieved from http://www.crlt.umich.edu/aboutcrlt/ab outcrlt

Centripetal force (2016). Retrieved from http://www.bing.com/knows/search?q=向心力\&mkt=zh-cn\&FORM= BKACAI.

Derek Bok Center for Teaching and Learning (2016). Retrieved from http://bokcenter.harvard.edu/about

Educational Innovation (2016). Retrieved from http://sydney.edu.au/education-portfolio/ei/.

Gardner, M. (2016). Retrieved from http://www.monash.edu/news/opinions/innovation-in-learning-and-teaching -is-too-important-to-cut

Guo, C., \& Sun, Q. (2015). A comparative analysis of Chinese universities and the world-class universities ---from the perspective of university rankings. Education Research, 2, 147-157,39-43.

He, Q. (2013). The practical issues and possible solutions of teacher education in comprehensive universities. Education Research, 11, 129-134.

Hoooper, B., Mitcham, M. D., Taff, S.D., Price, P., Krishnagiri, S., \& Bilics A. (2015). Energizing occupation as 
the center of teaching and learning. The American Journal of Occupational Therapy, 69(2), 1-5.

Introduction to Academic Leadership (2016). Retrieved from https://services.anu.edu.au/training/introductionto-academic- leadership-in-teaching-learning

Jin, Y., \& Xiao, L. (2014). On the value appeal of teacher education curriculum reform. Education Research, 5, 121-123.

Learning and Teaching Unit (2016). Retrieved from https://teaching.unsw.edu.au/ltu.

$\mathrm{Li}, \mathrm{Z}$. (2016). What is the world's leading university construction path to follow. Retrieved from Guangming Online.

Main Australian Rankings Table (2016). Retrieved from http://www. australianuniversities. com. au/rankings/.

Ministry of Education of the People's Republic of China (2015). Circular of the State Council on printing and distributing the overall plan for promoting the construction of world-class universities and first-rate disciplines. Retrieved from http://www.gov.cn/zhengce/content/2015-11/05/content_10269. htm\#.

Our Work at a Glance (2016). Retrieved from http://sydney.edu.au/education-portfolio/ei/aboutus/mission.htm.

Routledge (2009). Student engagement in higher education: theoretical perspectives and practical approaches for diverse populations. New York, NY.

STUDYSmarter (2016). Retrieved from http://www.student.uwa.edu.au/learning/studysmarter.

Taylor, L. (2005). Academic development as institutional leadership: An interplay of person, role, strategy, and institution. International Journal for Academic Development, 10(1), 31-46. https://doi.org/10.1080/136014 40500099985

The UQ Student Survey Framework (2016). Retrieved from http://www.uq.edu.au/teaching-learning/studentevaluation

The Williams Centre for Learning Advancement (2016). Retrieved from http://fbe.unimelb.edu.au/celt/

Zhong, Q. (2008). Research on innovating teacher education institution in China. Peking University Education Review, 6(3), 46-59,189.

Zhou, G., \& Wu, J. (2016). What is the world-Class discipline. China Higher Education Research, 1, 65-67.

\section{Copyrights}

Copyright for this article is retained by the author(s), with first publication rights granted to the journal.

This is an open-access article distributed under the terms and conditions of the Creative Commons Attribution license (http://creativecommons.org/licenses/by/4.0/). 